\title{
Residências multiprofissionais em saúde: um olhar ampliado para o cuidado
}

\author{
Pablo Guilherme Caldarelli \\ Graduação em Odontologia - UEL \\ Especialização em Ativação de Processos de Mudança na Formação Superior de Profissionais de Saúde - FIOCRUZ \\ Mestrado em Odontologia em Saúde Coletiva - UNICAMP \\ Doutorado em Odontologia (área: Cariologia) - UNICAMP \\ Docente do Departamento de Medicina Oral e Odontologia Infantil - UEL \\ Docente da Residência Multiprofissional em Saúde da Família - UEL \\ $\triangle$ pablocaldarelli@hotmail.com
}

Durante muitos anos as práticas de saúde no Brasil estiveram centradas no atendimento da demanda espontânea, com enfoque individual e abordagem técnica. Essas práticas pouco se relacionavam a um planejamento integrado das ações para o cuidado, estando voltadas apenas para a lógica de mercado. Com a criação do Sistema Único de Saúde (SUS), foram definidos princípios e diretrizes com o objetivo de garantir a população o direito de acesso e a cobertura universal à saúde como dever do Estado ("A saúde é direito de todos $e$ dever do Estado, garantido mediante políticas sociais e econômicas que visem à redução do risco de doença e de outros agravos e ao acesso universal e igualitário às ações e serviços para a promoção, proteção e recuperação". Constituição Federal de 1988, art. 196). Além disso, houve ampliação e qualificação das estruturas e processos de trabalho dos serviços de saúde, pautadas na lógica da atenção descentralizada, hierarquizada e regionalizada. Dessa forma, um crescente movimento passou a exigir novas tecnologias, habilidades e competências na formação de profissionais da saúde.

Neste contexto, em que a formação de profissionais da saúde constitui-se em um dos principais desafios para a efetivação e cumprimento dos princípios e diretrizes do SUS, o modelo das Residências Multiprofissionais em Saúde (RMS) surge com o intuito de formar um novo perfil de atuação para serviços e saúde e um "novo" olhar (ampliado) para o cuidado. As RMS encontram-se relacionadas à modalidade de ensino de pós-graduação lato sensu, estão destinadas à educação em serviço de profissionais que integram a área de saúde e, em sua grande maioria, são desenvolvidas em parcerias entre as Instituições de Ensino Superior (IES) e os serviços de saúde. 
As RMS operam na perspectiva da integração profissional entre as diversas áreas da saúde (a saber: Biomedicina, Ciências Biológicas, Educação Física, Enfermagem, Farmácia, Fisioterapia, Fonoaudiologia, Medicina Veterinária, Nutrição, Odontologia, Psicologia, Serviço Social e Terapia Ocupacional), baseada em práticas de humanização e comprometimento com o saber e poder coletivo, respondendo às reais necessidades de saúde dos usuários e território. Assim, as residências caracterizam-se pelo desenvolvimento de práticas multi/interdisciplinares e multi/interprofissionais que visam o cuidado integral à saúde do usuário, família e comunidade. Destaca-se, ainda, a capacidade de intervenção crítica e reflexiva na organização do processo de trabalho dos serviços de saúde e do trabalho em equipe, visando sempre à melhoria da qualidade de vida e saúde da população.

Em acréscimo, na perspectiva de um trabalho multi/interprofissional, as RMS visam a integralidade do cuidado e o gradativo abandono da visão curativista e individualista. Observa-se que as RMS surgem como uma importante estratégia para o rompimento de antigas práticas e a introdução de uma nova visão para os profissionais da saúde, sendo um dos principais objetivos a superação da segmentação do conhecimento e do cuidado em saúde. Outrossim, a atuação das RMS produz um saber potente na medida em que esta realidade é problematizada com a participação de professores, tutores e preceptores, visando à produção de propostas de intervenção sobre os problemas elencados e o fortalecimento da integração ensino, serviço e comunidade.

Neste cenário, o Ministério da Saúde (MS) vem apoiando as RMS há anos. As RMS foram criadas a partir da promulgação da Lei $n^{\circ} 11.129$ de 2005, sendo orientadas pelos princípios e diretrizes do SUS. Posteriormente, a Comissão Nacional de Residência Multiprofissional em Saúde (CNRMS) foi instituída por meio da Portaria Interministerial no 1.077, de 12 de novembro de 2009, coordenada conjuntamente pelo Ministério da Saúde (MS) e do Ministério da Educação e Cultura (MEC), tendo como principais atribuições: avaliar e acreditar os programas de RMS de acordo com os princípios e diretrizes do SUS para que atendam às necessidades sócio-epidemiológicas da população brasileira; credenciar os programas RMS bem como as instituições habilitadas para oferecê-los; registrar certificados das RMS, de validade nacional, com especificação de categoria e ênfase do programa. Ademais, o estabelecimento de financiamento regular para os programas de RMS no Brasil e o investimento na sua potencialidade pedagógica e política, tem por objetivo possibilitar 
tanto a formação de profissionais com esse "novo" olhar para o cuidado quanto contribuir com a mudança do desenho técnico assistencial do SUS.

\section{CONSIDERAÇÕES FINAIS}

As RMS podem ser consideradas uma das principais estratégias para se repensar o processo de formação em saúde, fortalecendo as ações para a integração ensino-serviçocomunidade. Além disso, ressalta-se a importância das RMS na formação de profissionais comprometidos e aptos para intervir de maneira crítica e reflexiva sobre o processo de trabalho dos serviços de saúde, com ênfase na integralidade, resolutividade e humanização do cuidado.

\section{REFERÊNCIAS}

BRASIL. Lei no 11.129/05. Institui as residências multiprofissionais e em área profissional da saúde. Brasília (DF), 2005.

BRASIL. Lei nº 8.080 de 19 de setembro de 1990. Lei Orgânica da Saúde. Brasília (DF), 1990.

BRASIL. Ministério da Educação e Cultura. Residência Multiprofissional [internet]. Brasília; 2018. [Acesso em 31 mar. 2018]. Disponível em: http://portal.mec.gov.br/residencias-em-saude/residencia-multiprofissional

BRASIL. Ministério da Educação. Resolução n 1 , de 30 de janeiro de 2012. Comissão Nacional de Residência Multiprofissional. Institui as Câmaras Técnicas da Comissão Nacional de Residência Multiprofissional em Saúde e dá outras providências. Diário Oficial da União 31 jan. 2012; Seção 1.

BRASIL. Ministério da Saúde. Secretaria de Gestão do Trabalho e da Educação na Saúde. Departamento de Gestão da Educação na Saúde. Residência multiprofissional em saúde: experiências, avanços e desafios. Brasília: Ministério da Saúde, Série B. Textos Básicos de Saúde, 2006. 414 p.

BRASIL. Portaria Interministerial $n^{\circ}$ 1.077, de 12/11/2009. Institui a Comissão Nacional de Residência Multiprofissional em Saúde. Ministério da Saúde. Ministério da Educação. Brasília (DF), 2009.

OSHIMA, A.M.M.Y.; BESEGATO, J.F.; LIMA, C.V.; NORONHA, M.S.; HOEPPNER, M.G.; CALDARELLI, P.G. Perfil, atuação e satisfação de cirurgiões-dentistas em Residências Multiprofissionais em Saúde da região Sul do Brasil. Revista da ABENO, v. 18, n.1, p. 134-145, 2018. 